See Article page 28.

\section{Commentary: The many shades of grey in thoracoabdominal aortic repair}

\author{
Jacques Tomasi, MD, and Amedeo Anselmi, MD, PhD
}

Thoracoabdominal aneurysm (TAA) repair remains a challenge with both open and endo approaches. Even though most of TAAs are manageable through an open repair, many patients will not endure such an approach. On one hand, open repair can achieve an excellent anatomic result with a considerable immediate risk; on the other, endovascular repairs are associated with lower immediate risk but are very demanding in endovascular skills and may require later reintervention. In addition, hybrid approaches are intended to diminish the operative risk than conventional open repair while facilitating the endovascular approach through surgical management of the efferent arteries. Finally, multiple endovascular strategies have been developed, the chimneys/snorkels techniques lie among them, and the current paper from a consolidated team clearly discusses its positioning in the toolbox. ${ }^{1}$ In particular, their positioning can be seen when the (even) more sophisticated fenestrated/branched devices are not available or insufficiently mastered.

In acute/complicated cases in which the objective is to save the patient's life, endovascular repair using chimneys or snorkels is an attractive solution, as they are easily available. Nonetheless, gutter leaks might severely impair the results, and some branches may be sacrificed to anchor the grafts. Such drawbacks can be at least in part addressed by approaches with customized fenestrated/branched

From the Division of Thoracic and Cardiovascular Surgery, Pontchaillou University Hospital, Rennes, France.

Disclosures: The authors reported no conflicts of interest.

The Journal policy requires editors and reviewers to disclose conflicts of interest and to decline handling or reviewing manuscripts for which they may have a conflict of interest. The editors and reviewers of this article have no conflicts of interest.

Received for publication Aug 18, 2021; revisions received Aug 18, 2021; accepted for publication Aug 20, 2021; available ahead of print Aug 26, 2021.

Address for reprints: Amedeo Anselmi, MD, PhD, Division of Thoracic and Cardiovascular Surgery, Pontchaillou University Hospital, 2 rue Henri le Guilloux, 35033

Rennes, France (E-mail: amedeo.anselmi@chu-rennes.fr).

JTCVS Techniques 2021;10:34-5

2666-2507

Copyright (C 2021 The Author(s). Published by Elsevier Inc. on behalf of The American Association for Thoracic Surgery. This is an open access article under the CC BY-NC-ND license (http://creativecommons.org/licenses/by-nc-nd/4.0/).

https://doi.org/10.1016/j.xjtc.2021.08.035
Check for updates

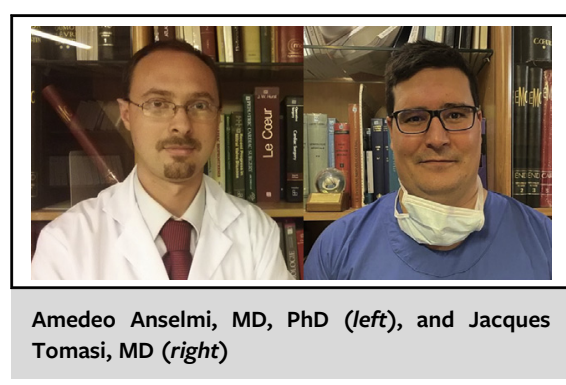

CENTRAL MESSAGE

The array of treatment options

for thoracoabdominal aneurysm

repair currently constitute many

"shades of grey," for which full

mastery is difficult for a single

team.

endoprostheses, which represents theoretically the highest point of "patient-specific" approaches in endovascular TAA repair. Notwithstanding, a recent series of physicianmodified stent grafts using antegrade laser fenestrations and image fusion guidance reported a $9 \%$ hospital mortality and a $42 \%$ rate of 1 -year reintervention, ${ }^{2}$ suggesting that even this strategy might be useful in nonelective cases as a bridge to a more durable repair. Custom-made branched endoprostheses can provide superior results (1\% operative mortality, $15 \%$ and $17 \%$ reintervention rate at 1 and 3 years, respectively), ${ }^{3}$ but their diffusion is hindered by availability and technical challenges.

At the same time, other authors believe that open repair remains the preferrable strategy in the majority of TAA cases; in a cohort of 393 patients (average age 63.2 years), the overall survival was $84 \%$ and $75 \%$ at 1 and 10 years, respectively. ${ }^{4}$ These represent nonetheless the "ideal" conditions among elective and relatively young candidates, and unfavorable predictors can be identified in the postdissection status and type 2 TAA. Finally, hybrid repair requires an abdominal approach, sequential clamping of target vessels, long operative time, and many patients may not undergo the second-stage intervention. A considerable incidence of complications is reported (spinal cord ischemia, myocardial infarction, mesenteric ischemia, and respiratory failure). Those strategies are performed in patients who are not fit for an open repair and if a total endovascular repair is also not feasible due to anatomical 
considerations or accessibility to these devices. Indeed, specific anatomic conditions may hinder endovascular repair and lead to uncertain results in term of endoleaks or target-vessel patency.

From open surgery, through hybrid repair, a chimneys/ snorkels approach until fenestrated/branched endoprostheses, many "shades of grey" exist in the toolbox for TAA repair (as well as in individual convictions), and it is difficult to provide definite recommendations, except the drive for vigilant innovation, multidisciplinary, and multiinstitutional cooperation.

\section{References}

1. Tanaka A, Oderich G, Estrera EA. Total abdominal debranching hybrid thoracoabdominal aortic aneurysm repair versus chimneys and snorkels. J Thorac Cardiovasc Surg Tech. 2021;10:28-33.

2. Sénémaud J, Fadel G, Touma J, Tacher V, Majewski M, Cochennec F, et al. Initial results of antegrade laser fenestrations using image fusion guidance and company manufactured stent grafts in complex aortic aneurysm repair. Eur J Vasc Endovasc Surg. 2021;62:204-13.

3. Gallitto E, Faggioli G, Pini R, Mascoli C, Ancetti S, Fenelli C, et al. Endovascular repair of thoraco-abdominal aortic aneurysms by fenestrated and branched endografts. Eur J Cardiothorac Surg. 2019;56:993-1000.

4. Shimamura J, Oshima S, Ozaki K, Sakurai S, Hirai Y, Hirokami T, et al. Open thoracoabdominal aortic aneurysm repair: contemporary outcomes for 393 elective cases. Ann Thorac Surg. 2019;107:1326-32. 